\title{
OS RESULTADOS ELEITORAIS DOS PARTIDOS POLÍTICOS NO BRASIL COMO REFLEXO DE SUA FORÇA ORGANIZACIONAL
}

\author{
Letícia Z. Bonaccorsi ${ }^{1}$
}

Isabela de Souza Gomes ${ }^{2}$

\begin{abstract}
Resumo
Com as constantes crises políticas na América Latina, pensar sobre os fatores dessa equação é essencial. Os partidos políticos são um desses fatores, e o presente trabalho propõe-se a analisar como essas agremiações se estruturam no Brasil. As análises sobre os partidos têm como objetivo a operacionalização do indicador de infraestrutura partidária, a partir de algumas variáveis. Ao final da pesquisa os dados dos partidos serão comparados entre si, possibilitando uma análise abrangente dentro dos diferentes espectros ideológicos. O objetivo geral é obter um quadro geral comparativo da infraestrutura partidária de todas as legendas no Brasil e com isso entender se tal fato gera melhores ou piores desempenhos eleitorais. Para analisarmos a competição eleitoral, utilizamos o resultado das eleições de 2018 para deputado federal no país, com objetivo de testarmos o índice de maneira prática. Para a definição em fortes, medianos e fracos, usamos um índice que estruturamos com base nas seguintes variáveis: i) densidade eleitoral; ii) complexidade organizacional; iii) idade do partido; iv) extensividade; v) justaposição parlamentar partidária; vi) capilaridade territorial. Este índice é uma adaptação e ampliação do modelo proposto por Bolognesi, Costa e Codato (2015) e Scarrow, Webb, \& Poguntke (2017). Os diferentes espectros ideológicos apresentam partidos em todos os níveis da escala, não sendo portanto suficiente para explicar a competitividade eleitoral. Ao pensarmos em um índice com variáveis múltiplas, podemos analisar com mais prudência o quanto a estrutura e sua força podem variar de partido para partido, que estratégias de atuação e alocação de recursos e poder podem ser distintas. Nosso objetivo é com base nos estudos de Tavits (2012), de que toda essa organização interna pode refletir em um maior resultado eleitoral, é fomentar o debate sobre a organização dos partidos em seu meio interno é fundamental para que possam manter-se atuantes.
\end{abstract}

Palavras-Chave: partidos políticos; organização partidária; força organizacional.

\section{INTRODUÇÃO}

Os partidos políticos são parte essencial para que aconteça o ápice do exercício da democracia representativa no Brasil: as eleições. A candidatura individual não é possível no país e, ainda que um candidato eleito possa seguir seu mandato sem um partido, é obrigatório que para concorrer a algum cargo público eletivo ele esteja filiado a alguma agremiação partidária. Isso coloca essas instituições

\footnotetext{
${ }^{1}$ Graduanda em Ciências Sociais, na Universidade Federal do Paraná. Pesquisadora do Laboratório de Partidos Políticos e Sistemas Partidários (LAPeS); letticia.bonaccorsi@gmail.com.

${ }^{2}$ Graduanda em Ciências Sociais, na Universidade Federal do Paraná. Pesquisadora do Laboratório de Partidos Políticos e Sistemas Partidários (LAPeS); isas.gomes16@gmail.com.
} 
num grau elevado de importância dentro de um sistema político que praticamente as não considera quando acabam as eleições. O que não significa dizer que os partidos sejam ponto de partida da tomada de decisão na hora do voto, uma vez que são uma das instituições com menor confiança da sociedade, mas sim que são essenciais ao jogo eleitoral.

A estrutura dos partidos brasileiros está organizada de acordo com o formato geral definido pela Lei dos Partidos Políticos, a Lei nº 9.096 de 1995, que determina a criação de órgãos e instâncias de decisão aos níveis municipal, estadual e nacional, além de conselhos especializados e de departamentos de representação setorial. No entanto, os partidos têm liberdade para se organizar de forma autônoma, e, assim, podem haver particularidades na atuação dos partidos a nível nacional e em relação aos estados. Dessa forma, analisamos a estrutural no nível macro, considerando que tal organização seja refletida nas outras instâncias, e também nos possibilita um resultado com um panorama mais geral da situação no Brasil.

O modo como as organizações partidárias se estruturam e funcionam demonstram características importantes sobre os modelos partidários e quais têm predominância dentro de um sistema partidário e político. De acordo com Panebianco (2005) e Katz \& Mair (1994), práticas organizacionais, regras internas, formação da coalizão dominante e o processo de seleção dos candidatos são variáveis de suma importância, pois demonstram como os atores políticos têm o acesso ao poder interno do partido político, assim como afetam as relações desses com a sociedade civil e o Estado.

Maurice Duverger (1980) também traz a discussão sobre os partidos políticos, com uma teoria geral em que tipifica os modelos de partido. Dentre as tipologias que o autor traz, o conceito de partido de massa é o que trabalha com características específicas que podem ser trazidas para o contexto das democracias modernas. Dentre as especificações deste conceito estão: a) organização interna de alta intensidade; b) origem extraparlamentar; c) forte articulação estrutural entre as instâncias partidárias; d) forte doutrinarismo; e) subordinação dos parlamentares ao partido; f) financiamento compartilhado entre os membros do partido; g) rigorosos requisitos de filiação (Duverger, 1980). Tais características são relevantes na construção do partido enquanto um competidor eleitoral mas também a de participante ávido da sociedade civil, uma vez que, a socialização interna dos partidos é uma forma de trocas sociais.

A infraestrutura tem como objetivo, portanto, solidificar uma agremiação partidária, seja no jogo eleitoral, como na atuação na sociedade. Sendo assim, com base na força da infraestrutura dos partidos no Brasil, pretendemos constatar se uma complexidade maior na estruturação leva a um 
resultado eleitoral mais satisfatório. Tal indagação é construída sob as colocações de Tavits (2012) e de Calvo \& Murillo (2004) de que a organização interna dessas agremiações é um fator especialmente significativo para um desempenho eleitoral positivo. O que é colocado, em especial por Tavits (2012) com seus estudos nas democracias da República Tcheca, Estônia, Hungria e Polônia no período pós comunista, é que, uma vez que os partidos têm uma disposição mais robusta de elementos que compõem a sua estrutura interna, a promoção da mobilização e da participação dos eleitores ocorre de forma mais orgânica e forte. Buscamos, neste trabalho, trazer uma contribuição ao debate acerca da relação entre organização partidária e sucesso eleitoral, no intuito de entender se os partidos mais organizados internamente são os que se encontram um bem sucedido resultado eleitoral, analisado neste artigo através do número de cadeiras alcançadas para deputado federal em 2018.

\section{MATERIAIS E MÉTODOS}

Para esse trabalho, a partir da discussão de Tavits (2012) e Calvo \& Murillo (2004), a hipótese que pretendemos testar é se partidos com maior força de infraestrutura apresentam maior sucesso eleitoral, ou seja, se eles se mostram capazes de converter a sua organização em cadeiras na Câmara dos Deputados. O trabalho de Tavits (2012) aponta para alguns fatores que podem ter maior peso na organização, descrevendo indicadores capazes de mensurar esta força nas legendas definidos a partir de três conjuntos de critérios: i) a quantidade de membros e sua atuação; ii) a extensividade da organização; iii) a profissionalização na organização central do partido.

Para esse estudo, utilizamos como recorte os deputados federais eleitos em 2018 no Brasil. Para realizarmos o teste da hipótese de que o porte da infraestrutura dos partidos influencia na relação com o sistema partidário, utilizaremos um método para mensurar a força organizacional, sendo este uma adaptação e ampliação do modelo proposto por Bolognesi, Costa \& Codato (2015) e Scarrow, Webb, \& Poguntke (2017). O índice é composto por variáveis que buscam abranger algumas faces da organização do partido, sendo critérios desde quantitativos, vislumbrando a estrutura de cargos do partido, a sua longevidade e critérios de atuação territorial. Ao propormos um índice com múltiplas variáveis, pretendemos não deixar que fatores diferentes tenham pesos diferentes. Assim como não levamos em consideração lideranças políticas de figuras carismáticas que podem elevar a um maior apreço popular pela legenda.

A partir do exposto anteriormente, classificamos as variáveis da seguinte forma: 
QUADRO 1 - QUADRO COM AS VARIÁVEIS DO ÍNDICE DE FORÇA ORGANIZACIONAL

\begin{tabular}{|c|c|c|}
\hline Nome da variável & $\mathrm{O}$ que se busca mensurar & Mensuração e fonte \\
\hline Densidade eleitoral & $\begin{array}{l}\text { Essa variável tem por finalidade } \\
\text { mostrar a aceitação que o partido tem } \\
\text { frente aos eleitores e sua capacidade } \\
\text { de cativá-los, sendo assim, quanto } \\
\text { maior a proporção de filiados entre os } \\
\text { eleitores. }\end{array}$ & $\begin{array}{l}\text { Mensuração: refere-se a quantidade } \\
\text { de filiados ao partido dividido pelo } \\
\text { número de eleitores do mesmo } \\
\text { partido na última eleição } \\
\text { Fonte: TSE }\end{array}$ \\
\hline Complexidade organizacional & $\begin{array}{l}\text { Trata-se de como o partido organiza- } \\
\text { se internamente, ou seja, as } \\
\text { secretarias e comissões que criam a } \\
\text { fim de atender demandas da } \\
\text { instituição (comunicação, relações } \\
\text { externas) assim como refletir } \\
\text { demandas da sociedade (secretaria de } \\
\text { mulheres, jovens). Essa variável } \\
\text { refere-se a quão profissionalizada é a } \\
\text { organização do partido, pois quanto } \\
\text { mais órgãos internos existirem, mais } \\
\text { profissionalizada e complexa tende a } \\
\text { ser a instituição. }\end{array}$ & $\begin{array}{l}\text { Mensuração: quantidade de órgãos } \\
\text { especializados. } \\
\text { Fonte: TSE }\end{array}$ \\
\hline Idade do Partido & $\begin{array}{l}\text { Foi medida em anos até o ano de } \\
\text { 2017, uma vez que imaginamos que } \\
\text { as estruturas sejam construídas } \\
\text { previamente às eleições em } 2018 . \\
\text { Quanto mais tempo de vida um } \\
\text { partido tem mostra o quanto é capaz } \\
\text { de sobreviver mesmo com mudanças } \\
\text { de lideranças e troca de governos } \\
\text { (Epstein, 2009). Com isso é possível } \\
\text { constatar que a organização do } \\
\text { partido está além dos membros que o } \\
\text { ocupam, possibilitando a adaptação } \\
\text { aos diferentes cenários (Panebianco, } \\
\text { 2005). Com uma idade maior, os } \\
\text { partidos conseguem se manter mais } \\
\text { fortes na memória do eleitor, } \\
\text { dispensando a informação completa e } \\
\text { consequentemente diminuindo o } \\
\text { custo do voto. }\end{array}$ & $\begin{array}{l}\text { Mensuração: a partir dos estatutos } \\
\text { de formação dos partidos. } \\
\text { Fonte: TSE }\end{array}$ \\
\hline Extensividade & $\begin{array}{l}\text { Refere-se a quantidade de membros } \\
\text { que ocupam a executiva do partido. } \\
\text { Quanto mais alta for essa variável, } \\
\text { menor é a chance de caciquismos } \\
\text { dentro da instituição, sendo assim } \\
\text { possibilitando uma maior } \\
\text { representatividade do eleitorado }\end{array}$ & $\begin{array}{l}\text { Mensuração: calcula-se quantos } \\
\text { membros fazem parte dos } \\
\text { diretórios. } \\
\text { Fonte:TSE }\end{array}$ \\
\hline Justaposição parlamentar-partidária & $\begin{array}{l}\text { Refere-se a quantidade de membros } \\
\text { que ocupam a executiva do partido e } \\
\text { não possuem cargos eletivos. Mostra } \\
\text { a capacidade do partido em inserir } \\
\text { membros não eleitos em cargos }\end{array}$ & $\begin{array}{l}\text { Mensuração: calcula-se quantos } \\
\text { membros que compõe os diretórios } \\
\text { e quantos deles possuem cargos } \\
\text { eletivos. } \\
\text { Fonte: TSE }\end{array}$ \\
\hline
\end{tabular}




\begin{tabular}{|l|l|l|}
\hline & $\begin{array}{l}\text { burocráticos, sendo assim, quanto } \\
\text { maior o número desse tipo de } \\
\text { membro, maior a força } \\
\text { organizacional do partido. }\end{array}$ & \\
\hline & $\begin{array}{l}\text { Essa variável mostra a presença do } \\
\text { partido nos municípios seja com } \\
\text { diretórios, seja com comissões } \\
\text { provisórias. Esse dado mostra a } \\
\text { capacidade extensão da atual } \\
\text { partidária frente os diferentes } \\
\text { cenários existentes dentro do país. } \\
\text { Isso mostra que ele possui uma } \\
\text { organização forte e ao mesmo tempo } \\
\text { uma base próxima aos eleitores, } \\
\text { sendo assim, as candidaturas lançadas } \\
\text { tendem a ter maior alcance, tornando } \\
\text { o custo menor. }\end{array}$ & $\begin{array}{l}\text { Mensuração: calcula-se em quantos } \\
\text { municípios do país há sedes do } \\
\text { partido. }\end{array}$ \\
Fonte: Borba e Cervi (2017) \\
\hline
\end{tabular}

Fonte: LAPeS/UFPR (2020)

Para as variáveis que não aplicadas de forma relacional (capilaridade e densidade eleitoral) o resultado dos partidos são apresentados de forma normalizada, aplicando-se a fórmula abaixo ${ }^{3}$, numa escala de 0 a 1, a fim de tornar possível a comparação entre as variáveis.

$$
y=\frac{\left(x_{i-} x_{\min }\right)(b-a)}{x_{\max -} x_{\min }}
$$

\section{RESULTADOS}

Inicialmente traçamos o índice conforme as categorias citadas anteriormente, definindo os partidos com força intrapartidária forte, média e fraca. Conforme a tabela abaixo.

TABELA 1: RESULTADOS DAS VARIÁVEIS

\begin{tabular}{|c|c|c|c|c|c|c|c|c|}
\hline PARTIDO & $\begin{array}{c}\text { DENSI } \\
\text { DADE }\end{array}$ & $\begin{array}{c}\text { COMPLE } \\
\text { XIDADE }\end{array}$ & IDADE & $\begin{array}{c}\text { MEMBROS } \\
\text { NA } \\
\text { EXECUTIVA }\end{array}$ & $\begin{array}{c}\text { JUSTA } \\
\text { POSIÇÃO }\end{array}$ & $\begin{array}{c}\text { CAPILA } \\
\text { RIDADE }\end{array}$ & SOMA & MÉDIA \\
\hline AVANTE & 0,00130 & 0 & 0,61765 & 0,07609 & 0,05556 & 0,23627 & 0,98686 & 0,16448 \\
\hline DEM & 0,00771 & 0 & 0,85294 & 0,23370 & 0,44444 & 0,62154 & 2,16034 & 0,36006 \\
\hline MDB & 0,01690 & 0 & 1 & 0,04348 & 0,22222 & 0,99838 & 2,28098 & 0,38016 \\
\hline NOVO & 0,00010 & 0 & 0 & 0,01087 & 0,00000 & 0,00144 & 0,01240 & 0,00207 \\
\hline
\end{tabular}

\footnotetext{
${ }^{3}$ Onde $x i$ representa o valor a ser convertido, $x$ min é o menor valor encontrado, $x$ maxo maior valor encontrado, 'b' o
} valor máximo da escala e 'a' o valor mínimo da escala da escala pretendida, aqui usamos a =0 e b =1 
Curitiba, 20 a 21 de agosto de 2020

\begin{tabular}{|c|c|c|c|c|c|c|c|c|}
\hline PATRIOTA & 0,00053 & 0,19231 & 0,08824 & 0,08696 & 0,11111 & 0,21921 & 0,69835 & 0,11639 \\
\hline PCB & 0,00278 & 0,30769 & 0,55882 & 0,03261 & 0,00000 & 0,00844 & 0,91035 & 0,15172 \\
\hline PCdoB & 0,00010 & 0 & 0,79412 & 0 & 0,05556 & 0,57361 & 1,42339 & 0,23723 \\
\hline $\mathrm{PCO}$ & 0,00002 & 0,19231 & 0,52941 & 0,01087 & 0,00000 & 0,00036 & 0,73297 & 0,12216 \\
\hline PDT & 0,00885 & 0,23077 & 1 & 0,10326 & 0,27778 & 0,81364 & 2,43431 & 0,40572 \\
\hline PHS & 0,00148 & 0 & 0,52941 & 0,04348 & 0,11111 & 0,42819 & 1,11367 & 0,18561 \\
\hline PMB & 0,00028 & 0 & 0 & 0,09783 & 0,00000 & 0,17217 & 0,27028 & 0,04505 \\
\hline PMN & 0,00156 & 0 & 0,73529 & 0,13043 & 0,05556 & 0,15978 & 1,08263 & 0,18044 \\
\hline PODE & 0,00114 & 0,15385 & 0,52941 & 0,10870 & 0,44444 & 0,22244 & 1,45998 & 0,24333 \\
\hline PP & 0,01015 & 0 & 0,58824 & 0,63043 & 1,00000 & 0,92549 & 3,15432 & 0,52572 \\
\hline PPL & 0,00028 & 0,30769 & 0,11765 & 1 & 0,00000 & 0,13716 & 1,56278 & 0,26046 \\
\hline PPS & 0,00339 & 0 & 0,67647 & 0,15217 & 0,00000 & 0,63339 & 1,46543 & 0,24424 \\
\hline PR & 0,00563 & 0 & 0,26471 & 0,11413 & 0,05556 & 0,27612 & 0,71614 & 0,11936 \\
\hline PRB & 0,00278 & 0,11538 & 0,29412 & 0,09783 & 0,00000 & 0,36912 & 0,87923 & 0,14654 \\
\hline PROS & 0,00066 & 0,42308 & 0,05882 & 0,16304 & 0,00000 & 0,51831 & 1,16391 & 0,19399 \\
\hline PRP & 0,00176 & 0 & 0,70588 & 0,28804 & 0,00000 & 0,16014 & 1,15582 & 0,19264 \\
\hline PRTB & 0,00096 & 0 & 0,52941 & 0,04891 & 0,05556 & 0,31472 & 0,94957 & 0,15826 \\
\hline PSB & 0,00461 & 0,57692 & 0,79412 & 0,19022 & 0,16667 & 0,92352 & 2,65606 & 0,44268 \\
\hline PSC & 0,00298 & 0 & 0,73529 & 0,09783 & 0,05556 & 0,34093 & 1,23259 & 0,20543 \\
\hline PSD & 0,00228 & 0,5 & 0,11765 & 0,26630 & 0,05556 & 0,58689 & 1,52868 & 0,25478 \\
\hline PSDB & 0,01027 & 0 & 0,76471 & 0,44022 & 0,44444 & 0,83357 & 2,49321 & 0,41553 \\
\hline PSDC & 0,00131 & 0 & 0,52941 & 0,13587 & 0,00000 & 0,30539 & 0,97198 & 0,16200 \\
\hline PSL & 0,00161 & 0,15385 & 0,5 & 0,11957 & 0,11111 & 0,48456 & 1,37069 & 0,22845 \\
\hline PSOL & 0,00104 & 0,26923 & 0,29412 & 0,13043 & 0,00000 & 0,14183 & 0,83665 & 0,13944 \\
\hline PSTU & 0,00012 & 0 & 0,58824 & 0,02174 & 0,00000 & 0,02029 & 0,63038 & 0,10506 \\
\hline $\mathrm{PT}$ & 0,01118 & 0,30769 & 0,97059 & 0,55435 & 0,05556 & 0,97235 & 2,87172 & 0,47862 \\
\hline РTB & 0,00841 & 1 & 1 & 0,88043 & 0,55556 & 0,68384 & 4,12824 & 0,68804 \\
\hline PTC & 0,00139 & 0 & 0,73529 & 0,03261 & 0,05556 & 0,35260 & 1,17745 & 0,19624 \\
\hline PV & 0,00265 & 0,38462 & 0,64706 & 0,29348 & 0,05556 & 0,64075 & 2,02411 & 0,33735 \\
\hline REDE & 0,00015 & 0,23077 & 0 & 0,16304 & 0,00000 & 0,12011 & 0,51407 & 0,08568 \\
\hline SD & 0,00141 & 0,53846 & 0,05882 & 0,15217 & 0,66667 & 0,36840 & 1,78594 & 0,29766 \\
\hline
\end{tabular}

Fonte: LAPeS/UFPR (2020) 
Com esses resultados podemos perceber como certas variáveis aumentam ou diminuem o valor final do índice. Isso nos possibilita perceber como partidos mais velhos de fato tem uma maior capilaridade dentro do país, por exemplo, apontando para uma possível relação entre elas e que geram um valor mais ou menos expressivo ao índice.

Para podermos classificar os partidos de acordo com a sua infraestrutura, definimos três categorias principais: forte, mediana e fraca, e para tal utilizamos o desvio padrão. Para partidos que tenham como valor do índice de zero até um valor do desvio padrão (de 0 a 0,14609) classificamos como fracos. Os que tenham valores no intervalo de um e dois de desvios padrões (de 0,1461 a 0,29218) como medianos e os que apresentem valores acima de dois desvios padrões (acima de 0,29219) como fortes. A classificação de todos os partidos está na tabela abaixo.

TABELA 2: ORDENAÇÃO POR NÍVEIS DE FORÇA

\begin{tabular}{|c|c|c|}
\hline PTB & 0,68804 & \multirow{10}{*}{ Forte } \\
\hline PP & 0,525719 & \\
\hline PT & 0,478619 & \\
\hline PSB & 0,442676 & \\
\hline PSDB & 0,415535 & \\
\hline PDT & 0,405718 & \\
\hline MDB & 0,380164 & \\
\hline DEM & 0,360057 & \\
\hline PV & 0,337352 & \\
\hline SD & 0,297656 & \\
\hline $\mathrm{PPL}^{4}$ & 0,260463 & \multirow{8}{*}{ Médio } \\
\hline PSD & 0,25478 & \\
\hline PPS & 0,244238 & \\
\hline PODE & 0,24333 & \\
\hline PC do B & 0,237231 & \\
\hline PSL & 0,228448 & \\
\hline PSC & 0,205431 & \\
\hline PTC & 0,196242 & \\
\hline
\end{tabular}

\footnotetext{
${ }^{4}$ Analisamos o PPL separado do PC do B porque a fusão dos partidos se deu somente no ano de 2019, após a eleição aqui observada.
} 


\begin{tabular}{|l|l|}
\hline PROS & 0,193985 \\
\hline PRP $^{5}$ & 0,192637 \\
\hline PHS $^{6}$ & 0,185612 \\
\hline PMN & 0,180438 \\
\hline AVANTE & 0,164477 \\
\hline DC & 0,161996 \\
\hline PRTB & 0,158261 \\
\hline PCB & 0,151724 \\
\hline PRB & 0,146539 \\
\hline PSOL & 0,139442 \\
\hline PCO & 0,122161 \\
\hline PR & 0,119357 \\
\hline PATRIOTA & 0,116392 \\
\hline PSTU & 0,105064 \\
\hline REDE & 0,085678 \\
\hline PMB & 0,045047 \\
\hline NOVO & 0,002067 \\
\hline
\end{tabular}

Fonte: LAPeS/UFPR (2020).

A partir dessa classificação testamos a hipótese, que os partidos classificados como fortes a partir do índice seriam os que teriam as maiores bancadas (PTB, PP, PT, PSB, PSDB, PDT, MDB, DEM, $\mathrm{PV}, \mathrm{SD})$.

\footnotetext{
5 Analisamos o PRP separado do Patriota porque a fusão dos partidos se deu somente no ano de 2019, após a eleição aqui observada.

${ }^{6}$ Analisamos o PHS separado do Podemos porque a fusão dos partidos se deu somente no ano de 2019, após a eleição aqui observada.
} 


\section{FIGURA 1: DEPUTADOS FEDERAIS ELEITOS POR PARTIDO EM 2018}

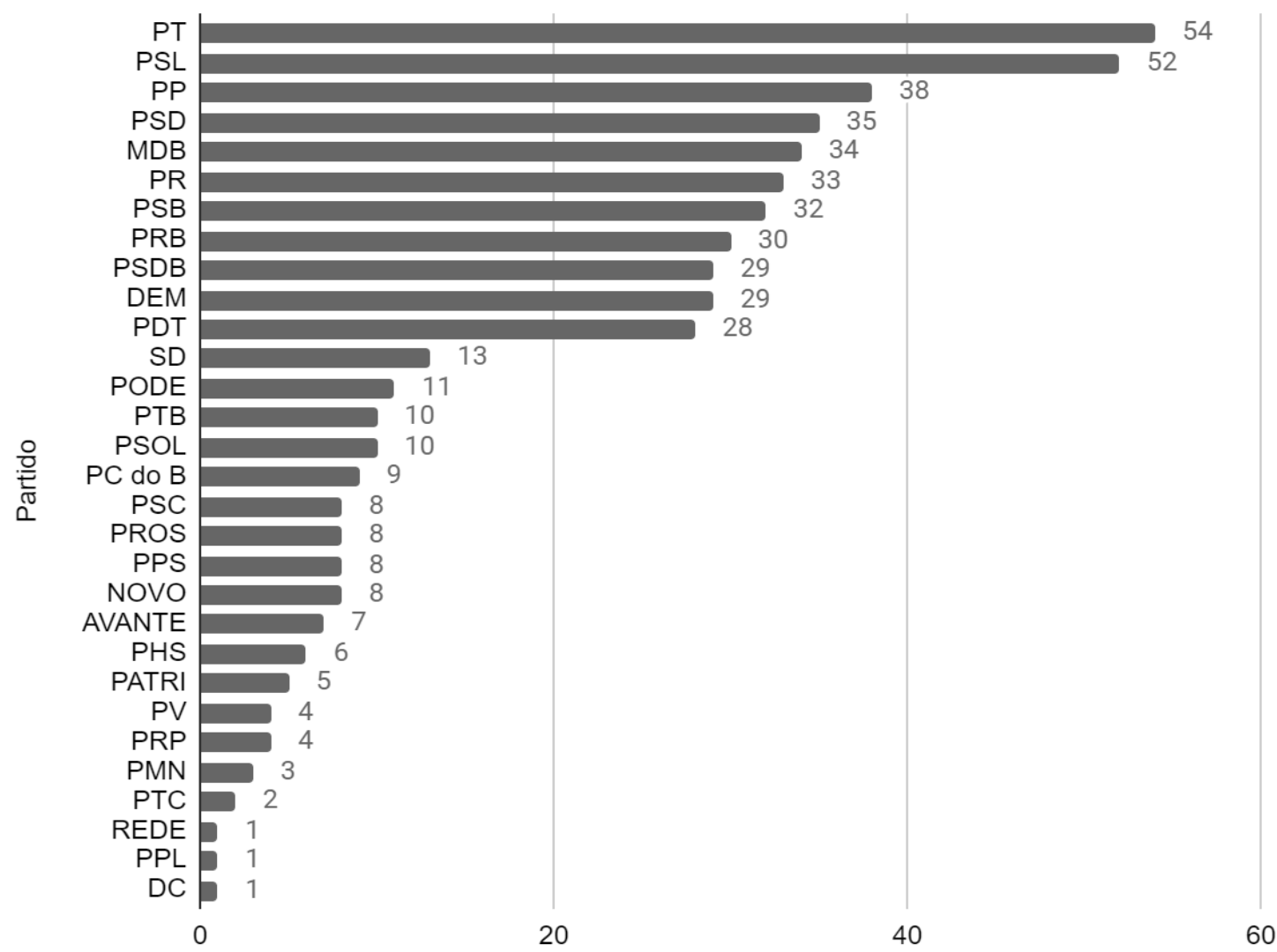

Número de cadeiras

Fonte: Câmara Legislativa.

Ao fazermos uma análise mais profunda, obtivemos os dados expostos na tabela a seguir:

TABELA 3 - CORRELAÇÃO ENTRE O NÚMERO DE CADEIRAS E O ÍNDICE DE FORÇA DOS PARTIDOS

\begin{tabular}{cccc}
\cline { 2 - 3 } & & Cadeiras & Força \\
\hline Cadeiras & $\begin{array}{c}\text { Correlação de } \\
\text { Pearson }\end{array}$ & 1 &, $517^{* *}$ \\
& $\begin{array}{c}\text { Sig. (2 } \\
\text { extremidades) }\end{array}$ & & 0,001 \\
\cline { 2 - 4 } & $\mathrm{N}$ & 35 & 35 \\
\hline Força & $\begin{array}{c}\text { Correlação de } \\
\text { Pearson }\end{array}$ &, $517^{* *}$ & 1 \\
\cline { 2 - 4 } & $\begin{array}{c}\text { Sig. (2 } \\
\text { extremidades) }\end{array}$ & 0,001 & 35 \\
\cline { 2 - 4 } & $\mathrm{N}$ & 35 & \\
\hline
\end{tabular}

**. A correlação é significativa no nível 0,01 (2 extremidades).

Fonte: Elaboração própria (2020). 
As variáveis apresentam um coeficiente de correlação de 0,517, o que denota que há uma linearidade positiva moderada entre ambas. Considerando, ainda, o valor do Sig $(0,001)$, podemos afirmar que há uma correlação significativa entre as variáveis. A hipótese que apresentamos aqui, portanto, de que há relação de dependência entre os níveis de infraestrutura dos partidos - fracos, médios e fortes - e o número de cadeiras ocupadas no Congresso Nacional apresenta uma correlação significativa no modelo proposto.

\section{FIGURA 1 - GRÁFICO DE DISPERSÃO DA CORRELAÇÃO ENTRE O NÚMERO DE CADEIRAS E O ÍNDICE DE FORÇA DOS PARTIDOS}

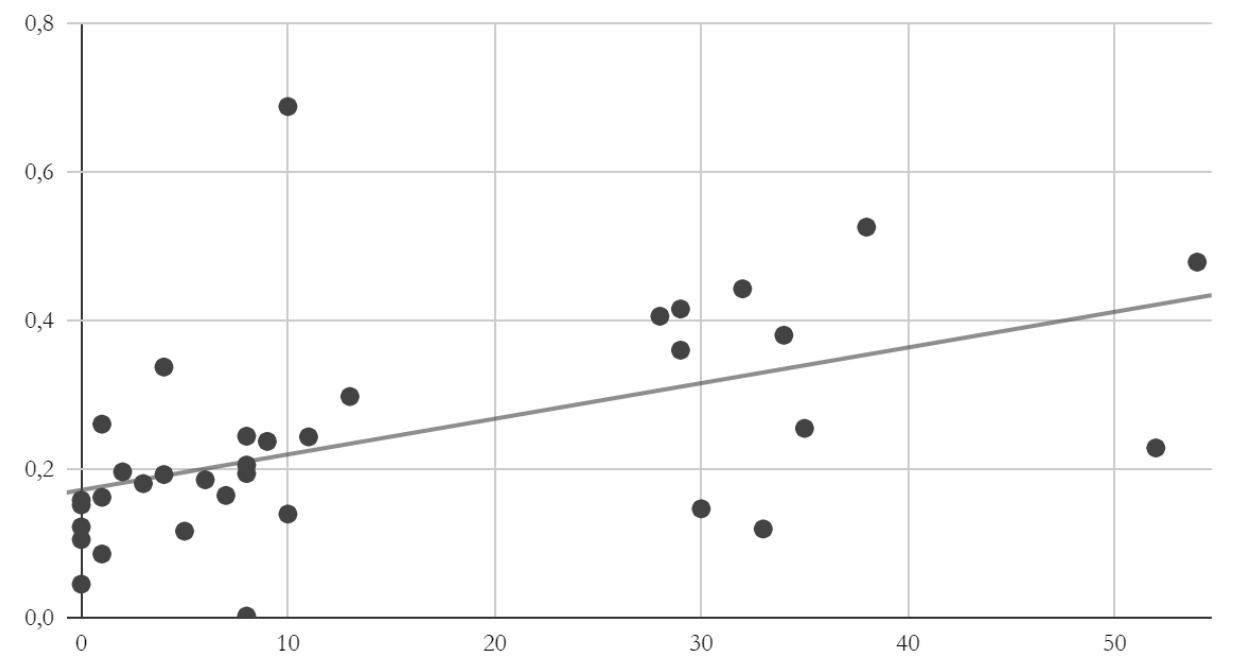

Fonte: Elaboração própria (2020).

O diagrama acima ilustra os dados de correlação apresentados na tabela 3, mostrando uma tendência positiva entre as variáveis. O gráfico demonstra, ainda, a correlação moderada apresentada anteriormente.

\section{CONSIDERAÇÕES FINAIS}

Sendo assim, o que se constata a partir do resultado das eleições do legislativo em 2018 e os dados acerca da infraestrutura partidos é que o nível de complexidade organizacional dos partidos, que envolve variáveis como a longevidade, capilaridade e profissionalização dos partidos, possui, de fato, influência sobre os resultados eleitorais. Contudo, como é possível constatar no gráfico da Figura 1, existem casos em que esta hipótese não se aplica. Os exemplos mais nítidos destes casos são partidos como o PV, que, apesar de apresentar um índice equivalente à categoria “forte”, possui um 
total de 4 cadeiras no Congresso, ou o PRB e o PR que, sendo partidos fracos, possuem 30 e 33 cadeiras, respectivamente. O PSL, citado anteriormente, também contraria a hipótese inicialmente apresentada no texto, possuindo a segunda maior bancada no Congresso - 52 cadeiras - mesmo sendo um partido de força média.

Estas constatações podem apontar que fatores como identificação ou o repúdio por algum espectro ou legenda, por exemplo, podem ser mais significativos na hora da tomada de decisão do eleitorado do que o enraizamento da estrutura do partido. No entanto, são capazes de apontar para a influência positiva que uma instituição de estrutura forte pode gerar na sociedade brasileira.

Em 2018, a já conhecida polarização se acentuou e refletiu em resultados que nosso índice não foi capaz de prever. Como dito anteriormente, a ideologia partidária não é contemplada no índice, no entanto, um fato que poderia se esperar é que partidos que seguem o padrão de Duverger e poderiam ser considerados de massas, originalmente mais ligados à esquerda, teriam organizações internas mais estruturadas. Tal fato poderia explicar o sucesso do PT, mas com certeza não explicaria o sucesso de seu opositor, que fez o segundo maior número de cadeiras, o PSL. As diferenças entre esses partidos estão para além da ideologia, suas secretarias, suas idades, suas permeabilidades na sociedade e até mesmo sua exposição na mídia tradicional, são completamente diferentes. Reforçando, portanto, que uma organização interna mais estruturada não gera necessariamente resultados eleitorais maiores, assim como uma disposição mais fraca não refletiria em baixos desempenhos.

De acordo com o que foi constatado por Tavits (2013) nos países do leste europeu, ou Calvo \& Murillo (2004) na Argentina, a força da estrutura organizacional gera, portanto, impacto no sucesso eleitoral no Brasil, sendo possível inferir que partidos com mais organização de fato tenham eleitores fiéis. O ano eleitoral 2018 trouxe novos debates considerando o universo das eleições no Brasil, mas o que nós pretendemos neste artigo é trazer um retrato de como os partidos brasileiros estão se organizando enquanto parte importante para a execução da democracia no país. E o que podemos constatar ao final desta análise é que a organização partidária não é essencial para o sucesso eleitoral dos partidos. Ainda que, conforme mostrado por Braga \& Pimentel Jr. (2011), a identificação com os partidos seja muito baixa no Brasil, o que ocorre é uma afeição (ou a falta dela) a um partido por parte do eleitor, levand que ele escolha esse ou aquela legenda na hora do voto e isso não pode ser relacionado com uma estrutura consolidada na sociedade que essa organização, mas sim a representação de uma causa ou demanda. Vale ressaltar que, por mais importantes que sejam as contribuições dos partidos para a manutenção da democracia, não se pode presumir a sua relevância 
nos resultados eleitorais, ou seja, não é possível afirmar de saída que os partidos possuem influência direta no sucesso eleitoral de seus candidatos.

É importante, ainda, considerar que, além da hipótese apresentada neste artigo, ainda é necessário verificar a importância da força organizacional dos partidos em outros níveis eleitorais além das nacionais, no caso das eleições estaduais e municipais. Seria necessário um estudo específico no intuito de constatar ou não esta possibilidade, até porque muitas vezes as estruturas tidas nos diretórios nacionais não conseguem ser replicadas nas outras instâncias dessas agremiações. Além disso, a força organizacional dos partidos pode ser considerada também para explicar outros fatores para além do sucesso eleitoral. Shomer, Put \& Gendalya-Lavy (2018), olhando para os casos da Bélgica e de Israel, apontam que fatores como a democracia interna dos partidos afetam os níveis de confiança que o eleitorado coloca nos partidos - partidos mais democratizados em seus processos internos tendem a conquistar mais a confiança do eleitorado. O que significaria que o partido seria capaz de ter uma força de pressão de demandas para além do período eleitoral e nas suas outras instâncias que não apenas a nacional.

\section{REFERÊNCIAS}

ALCÁNTARA, Manuel; FREIDENBERG, Flavia. Organización y Funcionamiento Interno de los Partidos Políticos en América Latina. Salamanca: Ediciones Universidad de Salamanca, 2001.

BOLOGNESI, Bruno; COSTA, Luis Domingos; CODATO, Adriano. A revolução silenciosa no Partido dos Trabalhadores no Brasil. In: Encontro Da Associação Brasileira De Ciência Política, 10, Belo Horizonte, p. 1- 27, 2016.

BORBA, Felipe; CERVI, Emerson Urizzi. Os diretórios partidários municipais e o perfil sociodemográfico dos seus membros. In: Anais Anpocs (pp. 1-23). Caxambu, 2017

BRAGA, Maria do Socorro Sousa. Organizações partidárias e seleção de candidatos no estado de São Paulo. Opinião Pública, vol. 14, n. 2, p. 454-485, nov. 2008.

BRAGA, Maria do Socorro Sousa; PIMENTEL JR, Jairo. Os partidos políticos brasileiros realmente não importam?. Opinião Pública, vol. 17, n. 2, p. 271-303, nov. 2011.

CALVO, Ernesto; MURILLO, Maria Victoria. Who delivers? Partisan clients in the Argentine electoral market. American Journal of Political Science, vol. 48, n. 4, p. 742-757, 2004.

CÂMARA LEGISLATIVA. Deputados Federais Eleitos em 2018. Dísponível em: $<$ https://www.camara.leg.br/internet/agencia/infograficoshtml5/DeputadosEleitos/index.html?fbclid=IwAR01Qq9pPwqiYTdQwcIk07RHSh80mgcoLDo0kcI6KUer8t2LhyvpsXsp2s> Acesso em: 14/05/2020, 
CODATO, Adriano Nervo; COSTA, Luis Domingos; CERVI, Emerson Urizzi. A direita brasileira em perspectiva histórica: uma socioanálise dos partidos de direita e dos seus políticos da democracia populista à democracia liberal (1945-2010). In Anais Anpocs. Águas de Lindóia, 2013.

DUVERGER, Maurice. Os Partidos Políticos. Brasília: Editora UnB, 1980.

LEVITSKY, Steven; ROBERTS, Kenneth M. The Resurgence of the Latin American Left. Baltimore: Johns Hopkins University Press, 2011.

MAIR, Peter. Party organizations: from civil society to the State. In: KATZ, Richard; MAIR, Peter (Eds.). How parties organize: change and adaptation in party organizations in Western democracies. Londres: Sage, p. 1-22, 1994.

MICHELS, Robert. Sociologia dos Partidos Políticos. Brasília: UnB, 1982.

PANEBIANCO, Angelo. Modelos de partido: organização e poder nos partidos políticos. São Paulo: Martins Fontes, 2005.

SHOMER, Yael; PUT, Gert-Jan; GEDALYA-LAVY, Einat. Does intra-party democracy affect levels of trust in parties? The cases of Belgium and Israel. Acta Politica, n. 53, p. 167-183, 2018.

TAROUCO, Gabriela da Silva; MADEIRA, Rafael Machado. Esquerda e direita no Brasil: uma análise conceitual. Revista Pós Ciências Sociais, 8, 171-186, 2011.

TAVITS, Margit. Party organizational strength and party unity in post-communist Europe. European Political Science Review, n .4, v. 3, 2012.

ZUCCO JR, César. Esquerda, direita e governo: a ideologia dos partidos políticos brasileiros. In: POWER, T.; ZUCCO JUNIOR, César (Ed.). O Congresso por ele mesmo: autopercepções da classe política brasileira. Belo Horizonte: UFMG, p. 37-60, 2011. 